\title{
Review of Dancing Parasites in Lymphatic Filariasis
}

\section{(ㄷ) (i) 요 $\ominus$}

\section{Authors}

Christoph F. Dietrich ${ }^{1}$, Nitin Chaubal ${ }^{2}$, Achim Hoerauf $^{3}$, Kerstin Kling ${ }^{4}$, Markus Schindler Piontek ${ }^{5}$, Ludwig Steffgen ${ }^{6}$, Sabine Mand ${ }^{3}$, Yi Dong7

Affiliations

1 Caritas-Krankenhaus, Medizinische Klinik 2, Bad Mergentheim, Germany

2 Thane Ultrasound Centre, Thane Ultrasound Centre, Thane, India

3 Institut für Med. Mikrobiologie, Immunologie und Parasitologie (IMMIP), Universität Bonn, Bonn, Germany

4 Department of Infectious Disease Epidemiology, Robert Koch-Institute, Berlin, Germany

5 Caritas Krankenhaus Bad Mergentheim, Academic Teaching Hospital of the University of Würzburg, Medical Clinic 2, Bad Mergentheim, Germany

6 Trainings-Zentrum Ultraschall-Diagnostik LS GmbH, Ultrasound, Mainleus, Germany

7 Zhongshan Hospital, Ultrasound, Shanghai, China

Key words

parasite, guideline, elastography, contrast-enhanced ultrasound

$$
\begin{array}{ll}
\text { received } & 28.11 .2018 \\
\text { revised } & 04.04 .2019 \\
\text { accepted } & 01.05 .2019
\end{array}
$$

Bibliography

DOI https://doi.org/10.1055/a-0918-3678

Ultrasound Int Open 2019; 5: E65-E74

(c) Georg Thieme Verlag KG Stuttgart · New York ISSN 2199-7152

\author{
Correspondence \\ Dr. Christoph F. Dietrich, MD \\ Caritas-Krankenhaus, \\ Medizinische Klinik 2, \\ Uhlandstraße 7, \\ 97980 Bad Mergentheim, \\ Germany \\ Tel : +49/7931/58 2201, Fax: +49/7931/58 2290 \\ Christoph.Dietrich@ckbm.de
}

\section{ABSTRACT}

Lymphatic filariasis is an infection transmitted by blood-sucking mosquitoes with filarial nematodes of the species Wuchereria bancrofti, Brugia malayi und B. timori. It is prevalent in tropical countries throughout the world, with more than 60 million people infected and more than 1 billion living in areas with the risk of transmission. Worm larvae with a length of less than $1 \mathrm{~mm}$ are transmitted by mosquitoes, develop in human lymphatic tissue to adult worms with a length of $7-10 \mathrm{~cm}$, live in the human body for up to 10 years and produce millions of microfilariae, which can be transmitted further by mosquitoes. The adult worms can be easily observed by ultrasonography because of their size and fast movements (the so-called "filarial dance sign"), which can be differentiated from other movements (e. g., blood in venous vessels) by their characteristic movement profile in pulsed-wave Doppler mode. Therapeutic options include (combinations of) ivermectin, albendazole, diethylcarbamazine and doxycycline. The latter depletes endosymbiotic Wolbachia bacteria from the worms and thus sterilizes and later kills the adult worms (macrofilaricidal or adulticidal effect).

\section{Introduction}

Parasitic diseases are rarely encountered in Europe and the clinical and imaging features are generally not well known. In the era of worldwide migration and refugees, knowledge of such diseases has gained importance as illustrated by multiple recently published reports of hydatid diseases [1-5], schistosomiasis [6, 7], fasciolosis [8], ascariasis [9], liver flukes [10], toxocariasis and other rare intestinal diseases $[11,12]$. This article describes the clinical and imaging features along with current treatment strategies for filariasis.
Across the world, nematodes (roundworms) cause a wide variety of parasitic infections of the subcutaneous and lymphatic tissue of almost all organs with significant economic and psychosocial damage. Three species, Wuchereria bancrofti ( $90 \%$ of lymphatic filariasis infections, humans are the only hosts), Brugia malayi (up to $10 \%$ of lymphatic filariasis infections, humans, domestic and wild animals are hosts), and $B$. timori, cause lymphatic filariasis (LF) affecting approx. 60 million patients worldwide [13]. Lymphangitis, lymphedema and the formation of fibrosis, sclerosis and scars are 
the pathophysiologically important sequelae. Loiasis and onchocerciasis are rarely associated with lymphedema.

LFI caused by $W$. bancrofti is common in the tropical regions of India and Southeast Asia, Pacific islands, Latin America and Caribbean area as well as in sub-Saharan Africa. B. malayi occurs mainly in China, India, Malaysia, Indonesia, the Philippines and the Pacific islands. B. timori occurs only on the Timor Island of Indonesia and some neighboring islands.

Nematodes are transmitted by mosquitoes. The mosquito vectors for filariasis vary geographically including the genus Culex, Anopheles, Aedes, Mansonia, and Coquillettidia. Humans are the so-called definitive host where the sexual stages develop. The adult worms do not replicate in humans. Therefore travelers have a short exposure to infective larvae and the disease ceases generally after a certain period. Transmission most often happens in childhood $[14,15]$. The disease is almost not detected in travelers and very rarely in expatriates.

The larvae develop into mature adult worms, which mate and produce sheathed microfilariae with mainly nocturnal periodicity. In addition, a mosquito ingests the microfilariae again during a blood meal; these develop into larvae, which can infect another human when the mosquito takes a subsequent blood meal, completing the life cycle.

The prevalence increases with age. Travelers usually have insufficient exposure to filariasis to develop sufficiently high worm burdens. More often a local hypersensitivity including eosinophilic infiltrate with lymphangitis and lymphadenopathy, urticaria, and peripheral eosinophilia is observed.

Humans are infected during a blood meal. The mosquito-transmitted larvae develop into mature adult worms in about 9 months. The adult parasites can be observed in lymphatic vessels. Larvae appear in the blood stream after a prepatent period of about 12 months. They often show periodic activity in the blood stream. In areas with mosquitos that are active at night, the larvae appear in the blood in astonishingly precise nocturnal periods. In areas with mosquitos that are active during the day, the larvae can be detected in the blood during the day, e. g., Brugia malayi. The adult worms survive for approximately five years. The size of the filariae is species-dependent from $10-100 \mathrm{~mm}$ in length and $0.07 \times 0.1 \mathrm{~mm}$ in width. In ultrasound images the echoes appear bigger than the real worm. Measurements resulted in echoes of up to $2.5 \mathrm{~mm}$.

Filarial disease is influenced by the extent and duration of exposure to infective mosquito bites, i. e., the quantity of accumulating adult worm antigen in the lymphatics. The adult worms in the lymphatics induce an inflammatory response [16] but also mechanical damage [17]. As rickettsia-like organisms, Wolbachia are endosymbiotic to adult worms [18] and may be responsible for the inflammatory changes [19-24]. Treatment with antibiotics such as doxycycline or rifampicin kills Wolbachia and as a result the adult worms become sterile and can no longer reproduce. As such, treated patients are no longer infectious.

\section{Symptoms and Clinical Manifestations}

Only one third of infected patients develop overt symptoms [25]. Symptoms range from asymptomatic to severely disabling. The severity of symptoms and the course of the disease are determined by the extent and duration of the exposure to infective mosquito bites, the quantity of accumulating adult worm antigen in the lymphatics, the host immune response, and the number of secondary bacterial and fungal infections.

\section{Acute disease}

Acute disease is caused by spontaneous or drug-induced death of adult filariae, with filarial fever, chills, acute lymphadenopathy (with retrograde lymphangitis, mainly the inguinal lymph nodes), myalgia and tropical pulmonary eosinophilia with microfilariae trapped in the lungs characterized by nocturnal wheezing [26]. In general, the recurrent acute inflammation occurs once, twice or five times a year and resolves after few days to one week depending on severity [27-29].

\section{Chronic disease}

Local symptoms (pitting lymphedema, hydrocele) are the prominent signs of chronic infection within the skin and the surrounding tissues, especially the lower extremities [30]. The mechanism might be partially explained by bacterial superinfection (e. g., interdigital microtrauma), and once the lymphatic vessels are damaged, lymphedema may progress even in the absence of filarial infection [31]. In Brugian filariasis ulcerating abscess formation may occur along the involved lymphatics including the genitalia. Many organs can be involved, including the scrotum (scrotal lymphangiectasia, hydrocele up to $30 \mathrm{~cm}$, epididymitis and rarely orchitis),
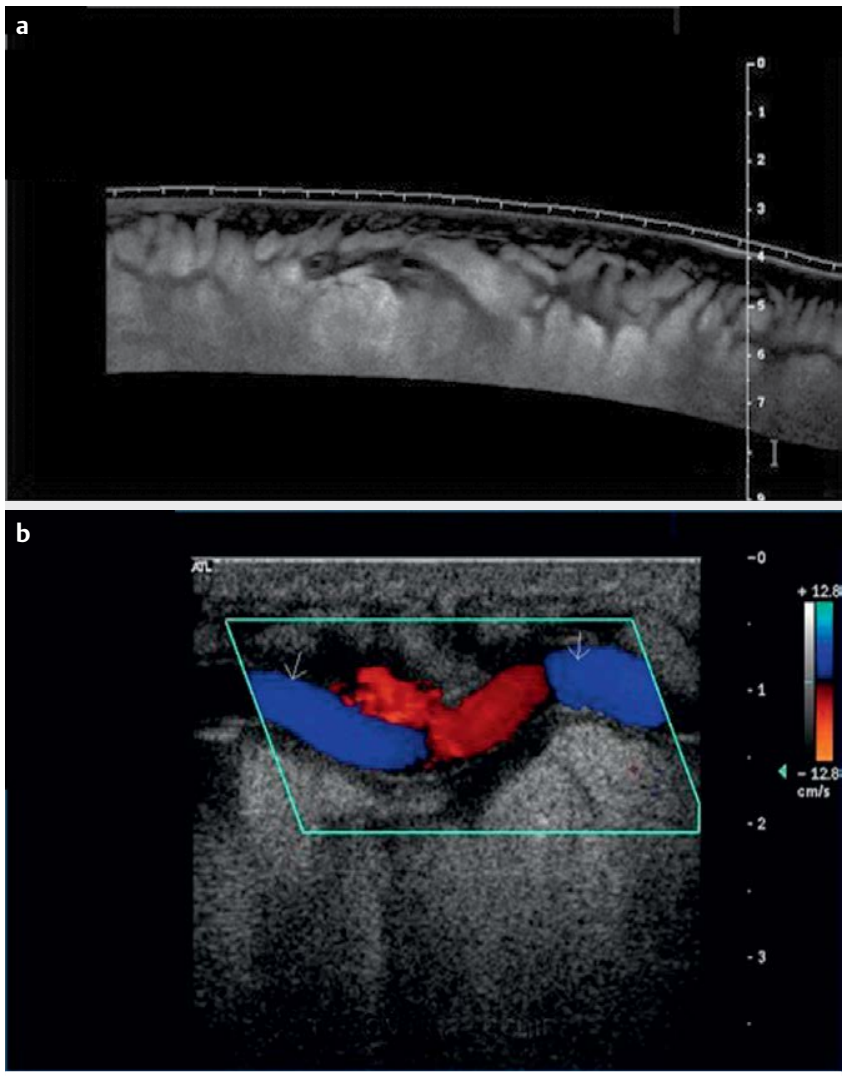

- Fig. 1 Leg filariasis, B-mode imaging of leg filariasis a, color Doppler imaging of leg filariasis $\mathbf{b}$ in a patient with subcutaneous thickening. 

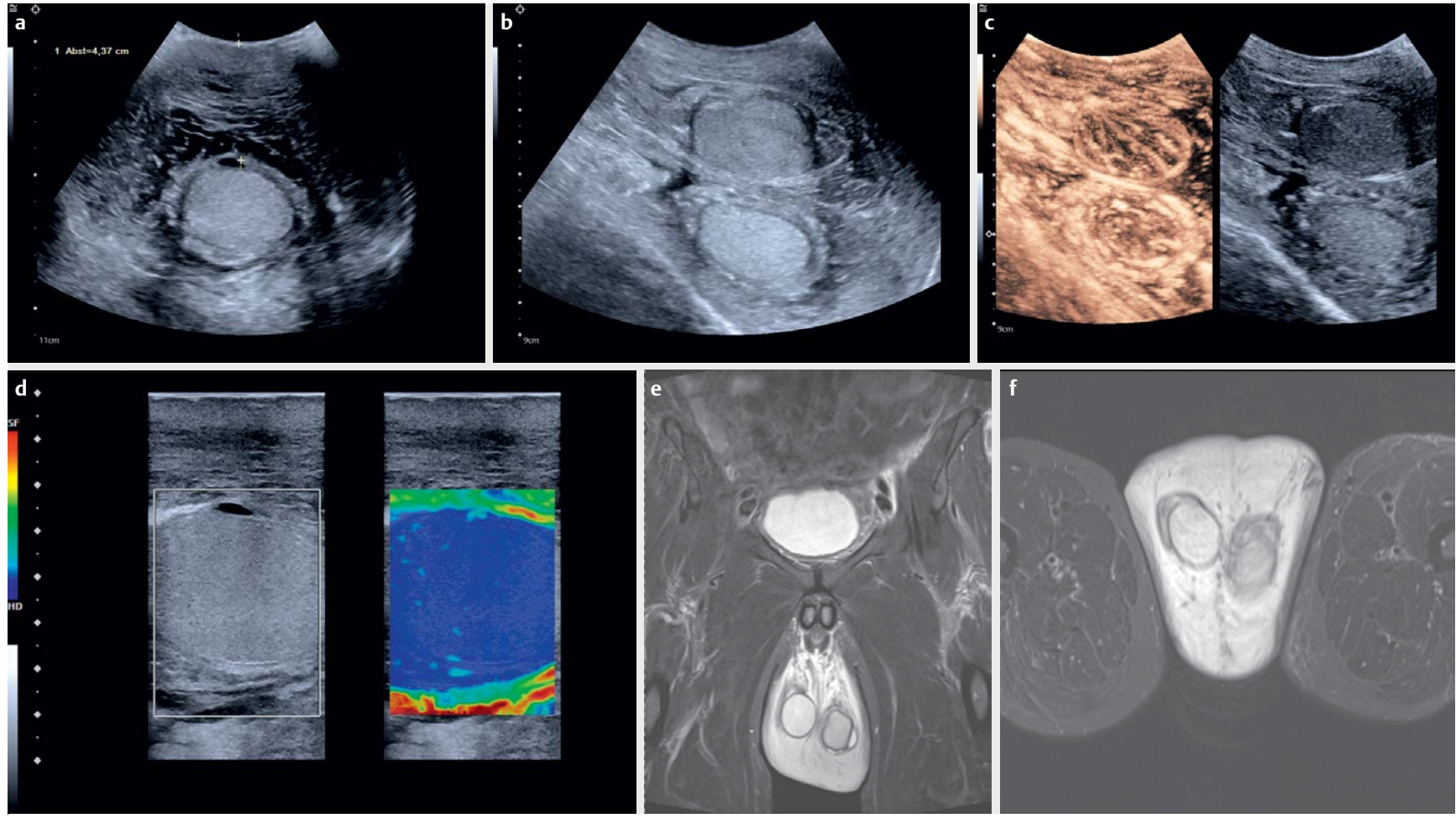

> Fig. 2 60-year-old patient from Guatemala, Latin America with recurrent scrotal swelling with thickness of the pure scrotum without testis of $>40 \mathrm{~mm}$ a and $\mathbf{b}$, the swelling is indicated between markers) on both sides $\mathbf{b}$. A hydrocele was operated on a few years ago. Treatment with mebendazole has been reported during that time. The "filarial dance sign" could be seen on real-time ultrasound below the testis. The testes showed increased stiffness using elastography $\mathbf{c}$ and little contrast enhancement on contrast-enhanced ultrasound $\mathbf{d}$, indicating chronic orchitis. MRI images (T2, koronar) are also shown $\mathbf{e}, \mathbf{f}$.
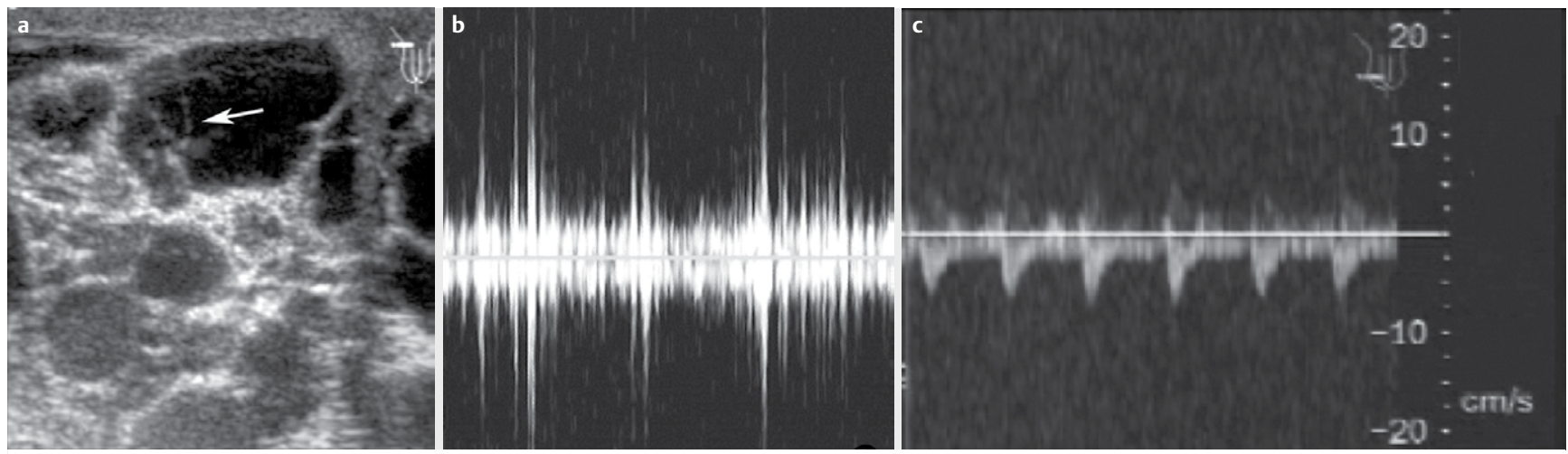

- Fig. 3 Ultrasound of enlarged lymph vessels in the scrotal area; in the left part of the biggest vessel, a moving worm can be detected a. On pulse wave Doppler, the movements appear as irregular amplitudes $\mathbf{b}$ and can be differentiated from pulsating vessels $\mathbf{c}$.

urogenital and renal manifestations [32-34] with chyluria (intestinal lymph may be intermittently discharged into the renal pelvis [35], ovary and inner genital [36], eyes and heart. The hydrocele is a fluid collection between the parietal and visceral layers of the tunica vaginalis, surrounding the testis and spermatic cord. Progressive non-pitting lymphedema with limb swelling is related to chronic inflammation of the lymphatic vessels resulting in hyperpigmentation and hyperkeratosis and sometimes elephantiasis of the lower limbs. The breast can be involved in females.

\section{Diagnosis}

\section{Confirming serological diagnosis}

Blood eosinophilia is typical, sometimes exceeding $3 / n L$ [26] and serves as screening in patients with typical symptoms. Diagnosis of $\mathrm{LF}$ can be best achieved by detecting circulating filarial antigen (CFA) of W. bancrofti-DNA in the blood [37-43], detecting circulating microfilariae or by detecting adult worms in the lymphatics [44]. Examination of blood smears is a less sensitive but acceptable 

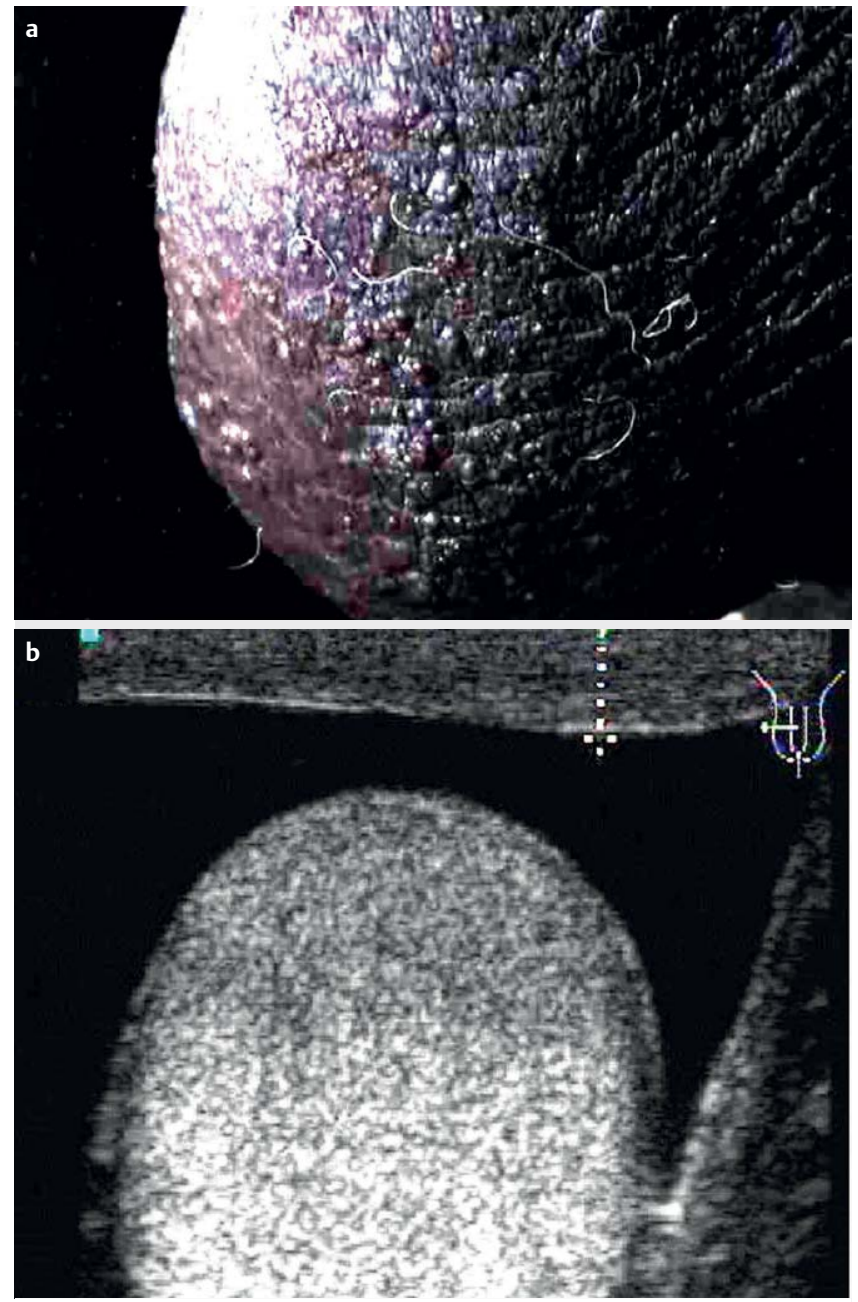

- Fig. 4 Lymph scrotum with thickened skin a. Thickness can be measured by ultrasound $\mathbf{b}$.

alternative in settings where antigen testing is not available. Blood tests have better sensitivity than biopsy and histological evaluation $[45,46]$. CFA is diagnostic in $W$. bancrofti only but false-positive $W$. bancrofti antigen testing may occur in patients with severe circulating Loa loa microfilariae $[47,48]$. Negative blood results have been observed in treated "burned out" infections $[46,49,50]$. Definitive diagnosis of filariasis requires blood smear examination for microfilariae or the presence of circulating filarial antigen. Serological testing may be helpful in appropriate clinical settings. Unless they use the single recombinant antigen Wb 123 (which is not commercially available) [51], antifilarial serologic antibody tests do not differentiate between the various types of filarial infections and often show a cross-reaction with antigens from other diseases caused by helminths [52]. They do not allow differentiation between acute and chronic infection [53]. Species-specific polymerase chain reaction techniques have been used but they are not commercially available [54,55]. Examination of concentrated [56] blood smears using Giemsa or Wright stains (taken during the nocturnal activity period) for microfilariae is a second-line diagnostic tool if circulating antigen testing is not available or Brugian filariasis is suspected $[57,58]$. Morphologic characteristics on blood
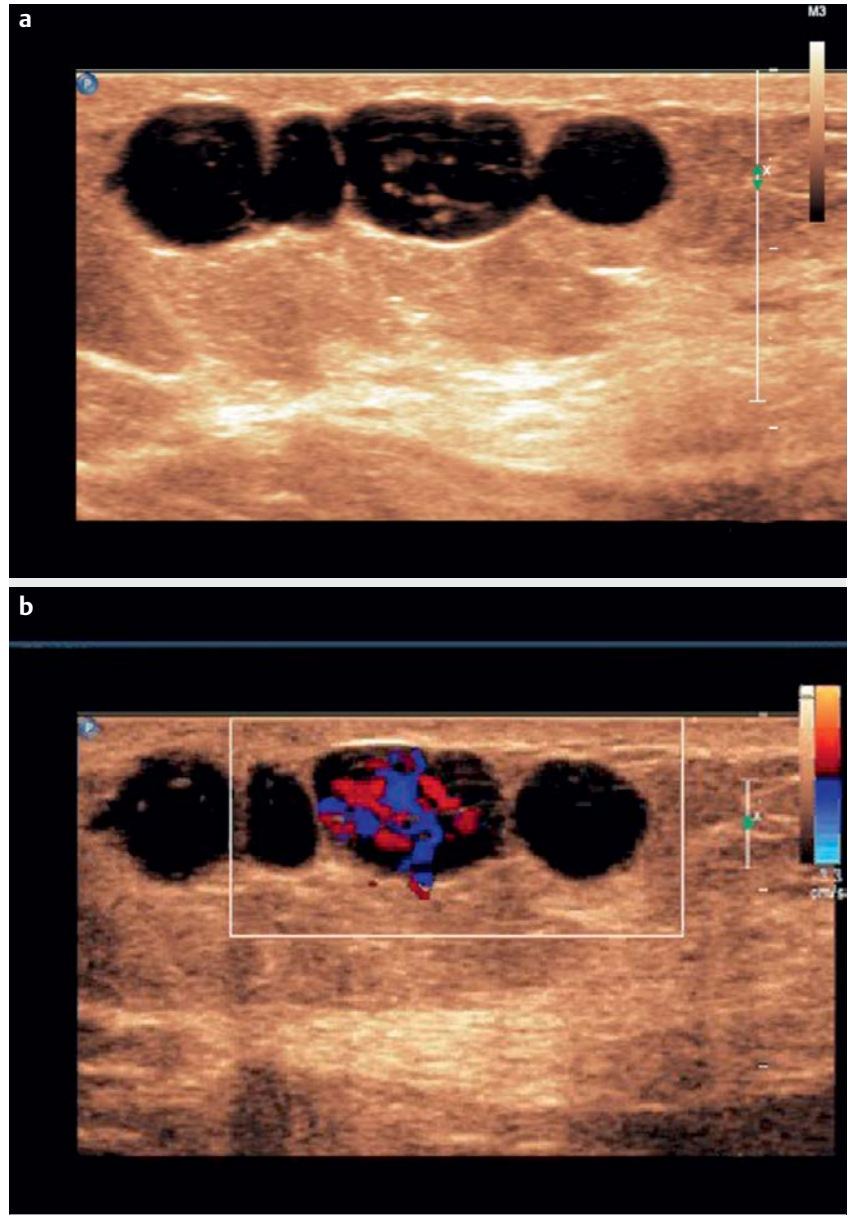

- Fig. 5 Breast filariasis. B-mode imaging a and color Doppler imaging of breast filariasis $\mathbf{b}$. Irregular amplitudes of color signals could be used to make a differential diagnosis.

smear allow differentiation of the LF species. W. bancrofti and both Brugia species have an acellular staining sheath visible on light microscopy. W. bancrofti has no nuclei in its tail whereas $B$. malayi has terminal and subterminal nuclei in its tail.

\section{Imaging diagnosis}

Imaging in general and ultrasound specifically may demonstrate the parasites' respective complications [59-63]. Damaging conventional X-ray contrast lymphangiography has been replaced by scintigraphy [33].

$X$-ray lymphangiograms made in patients with filarial lymphedema show a typical pattern of varicosities which clearly differentiate this condition from lymphostatic verrucosis, the prevalent form of non-filarial lymphedema [64]. Also, lymphography was useful in the treatment of chyluria [65]. Contrast lymphangiography, while widely used to visualize the morphology of the lymphatic vessels [66], carries the potential risk of lymphatic damage. The unpredictable consequences of such studies have hampered the early evaluation of the lymphatics of asymptomatic individuals [67]. To overcome these difficulties, lymphoscintigraphy using radiolabeled albumin or dextran has been developed [68]. This technique can be performed and repeated safely so that serial studies of individuals 

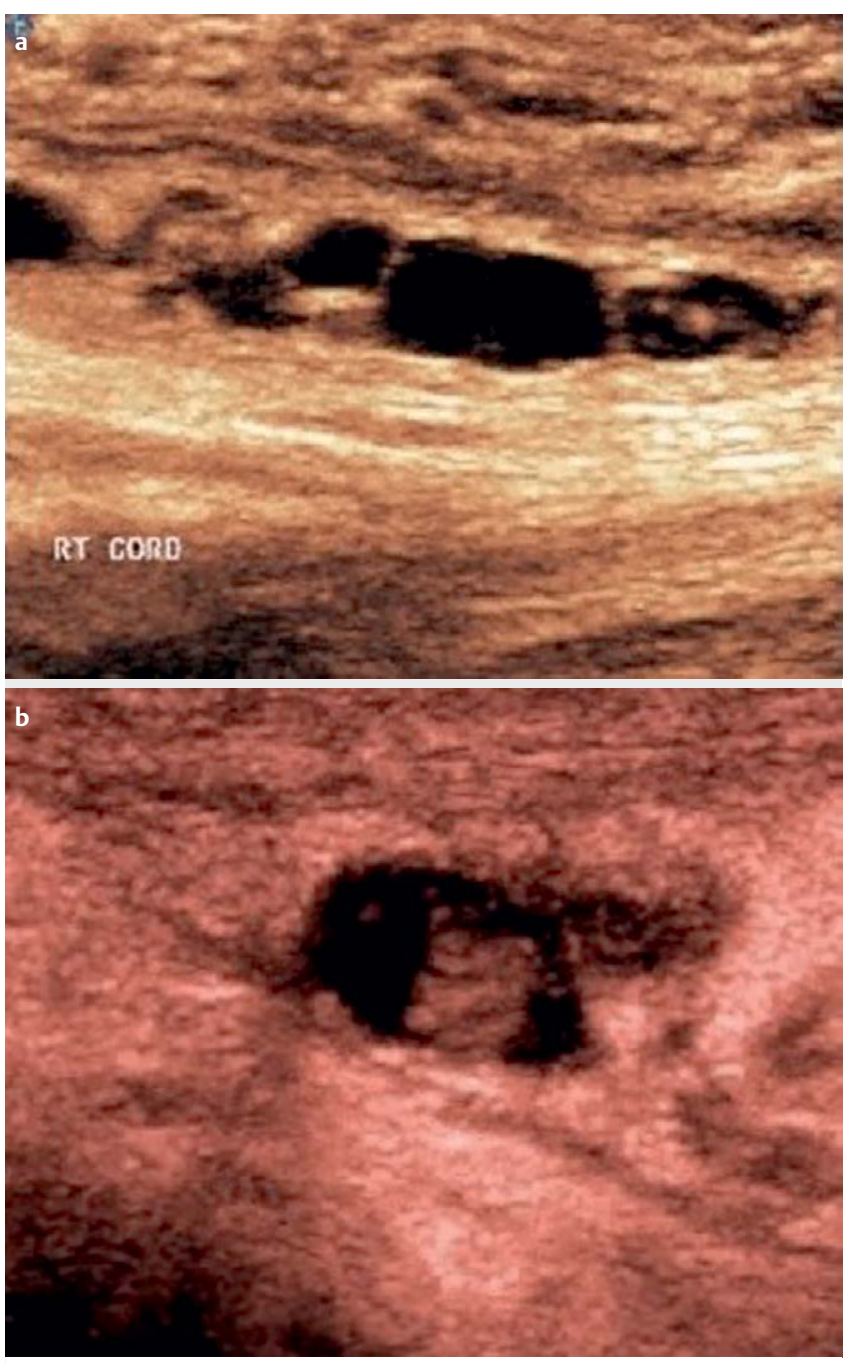

- Fig. 6 Cord filariasis, grayscale imaging of cord filariasis a, detailed view of small adult worms $\mathbf{b}$.

are possible. Preliminary studies with this technique have demonstrated the presence of lymphatic abnormalities in asymptomatic microfilaremics with no evidence of edema. Lymphoscintigraphy allows clear and precise analysis of lymphatic system function in patients at risk. This technique could be used for the examination of infected but asymptomatic individuals to determine whether they have morphological or functional lymphatic abnormalities and how these alterations could be changed, especially by chemotherapy. It could also provide a new epidemiological tool for detailed studies of morbidity due to endemic filariasis.

Ultrasound allows the detection of moving adult worms in lymphatic vessels ("filarial dance sign") and also monitoring of the effectiveness of treatment [69-77] ( $\vee$ Video 1). Pulsating blood vessels can be differentiated from irregular moving worms containing lymphatics by Doppler ultrasound [78-81] ( Video 2). The "filarial dance sign" has been observed in many organs including the limbs [71, 80] - Fig. 1, scrotum [69, 70, 72-74, 82-84] $>$ Fig. 2 and - Fig. 3, breast and axillary lymphatics [75, 78, 85, 86] - Fig. 4 and - Fig. 5 or cord $>$ Fig. 6 . The role of different ultrasound techniques in evaluating lymphatic disease has been extensively described
[87-95]. The role of contrast-enhanced ultrasound [88, 96-102] and elastography [99-101, 103-106] in the evaluation of filariasis has not yet been described. Both methods might be helpful in identifying fibrosis and scars. Contrast-enhanced ultrasound can also be used to evaluate the lymphatic tissue directly $[107,108]$.

Almost no helpful and specific experience has been published about CT [109-111] and MRI [112-115] findings in filariasis also due to the small size of the parasites.

\section{Differential Diagnosis}

The differential diagnosis of LF with retrograde lymphedema includes primary lymphedema, progressive cellulitis, neoplastic diseases (e. g., cancer) and a variety of inflammatory diseases (e. g., antegrade bacterial lymphangitis, tuberculosis), as well as loiasis, onchocerciasis, podoconiosis (abnormal inflammatory reaction to mineral particles in altitudes higher than mosquito transmission zones for filariasis (above $1500 \mathrm{~m}$ )) [116]. Loiasis and onchocerciasis are rarely associated with lymphedema.

The filarial nematode $L$. loa causes loiasis. The diagnosis is established by identifying the migrating adult worm in the subcutaneous tissue swelling (calabar) of the distal limbs and during the subconjunctival migration of the worm around the orbita or by detecting microfilariae in a blood smear $[47,117,118]$. False-positive antigen tests for $W$. bancrofti in the setting of $L$. loa microfilaremia may complicate the diagnosis of occult $W$. bancrofti in coinfected patients.

The filarial nematode Onchocerca volvulus causes onchocerciasis. The clinical manifestations include skin and eye involvement and systemic manifestations. The so-called "hanging groin" is a result of skin atrophy of the groin and anterior thigh. Chains of (scary) lymph nodes result in folds of loose skin.

\section{Treatment}

Early treatment is recommended also in asymptomatic patients to prevent lymphatic disease. In patients with advanced disease with scars and fibrotic tissue, treatment success is less obvious. The treatment of local and systemic secondary bacterial infections is mandatory and includes regular antibiotics and prophylactic antibiotics in some cases and the use of antibacterial creams on damaged skin and small erosions. Careful attention to hygiene including regular nail cleaning, wearing of shoes, washing of affected areas daily, etc. is important. The affected limb(s) should be regularly exercised and if necessary lymph flow should be enhanced by complex decongestive therapy (CDT). Elevation of the affected limb during the night is recommended after the exclusion of arterial occlusive disease.

The standard treatment of choice in monoinfection of Wucheria bancrofti, Brugia malayi, and Brugia timori is diethylcarbamazine (DEC, $6-10 \mathrm{mg} / \mathrm{kg}$ for up to 2 (3) weeks) [1, 119-121]. The dosage and mechanism of action depend on the species [122-124]. DEC is not recommended in pregnancy.

Patients with proven or suspected coinfection of LF and onchocerciasis without ocular involvement should undergo treatment of onchocerciasis first. LF pre-treatment in the form of ivermectin $150 \mu \mathrm{g} / \mathrm{kg}$ in a single dose should be given to reduce the microfilarial load [124-129]. Ivermectin can be followed by the above- 
mentioned standard treatment for LF, DEC after one month or later $[130,131]$. Doxycycline (200 mg orally once daily for four to six weeks) followed by ivermectin $(150 \mu \mathrm{g} / \mathrm{kg}$ orally single dose) can be used as an alternative to the standard treatment [132]. It is macrofilaricidal, i. e. it kills the adult worms and constitutes a curative therapy.

Albendazole shows at least partial macrofilaricidal activity against adult worms and has been effective and safe in patients with concomitant loiasis or onchocerciasis [133,134]. Complex lymphatic decongestive physiotherapy should accompany drug treatment.

Surgical drainage of hydroceles may give immediate relief but recurrence may occur [19].

The reproductive lifespan of adult parasites has been estimated to be 4-6 years, explaining the effectiveness of mass treatment programs (Global Program for the Elimination of LF) [121, 135-138]. Such programs have suppressed transmission to $<1$ percent. $W$. bancrofti has no animal hosts and might be the best target for elimination. Other filariases, e. g., Brugian, have a domestic and wild animal reservoir and elimination does not seem feasible. Triple-drug single dose treatment with ivermectin, diethylcarbamazine, and albendazole has been successful in endemic areas $[139,140]$.

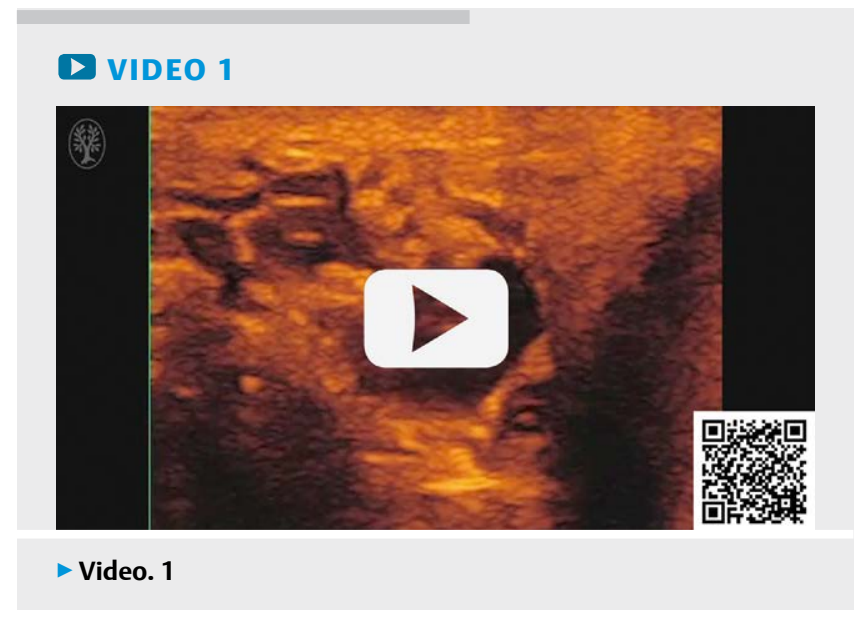

$\checkmark$ VIDEO 2

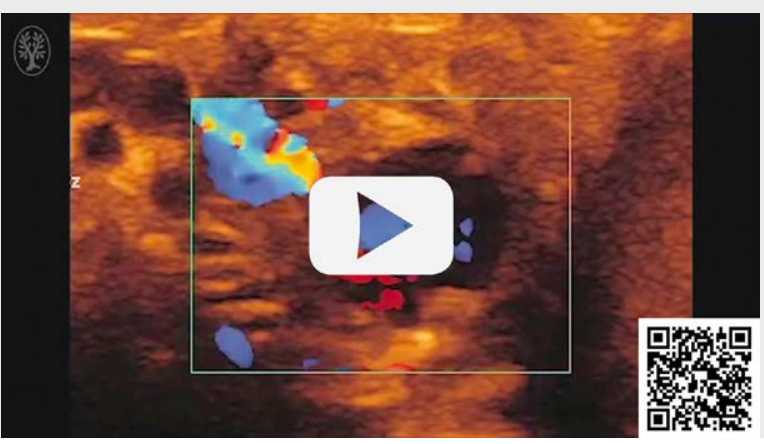

Video. 2
Conflict of Interest

Authors declare that they have no conflict of interest.

References

[1] Dietrich CF, Lorentzen T, Appelbaum L, Buscarini E, Cantisani V, Correas JM, Cui XW et al. EFSUMB Guidelines on Interventional Ultrasound (INVUS), Part III - Abdominal Treatment Procedures (Long Version). Ultraschall Med 2016; 37: E1-E32.

[2] Dietrich CF, Lorentzen T, Appelbaum L, Buscarini E, Cantisani V, Correas JM, Cui XW et al. EFSUMB Guidelines on Interventional Ultrasound (INVUS), Part III - Abdominal Treatment Procedures (Short Version). Ultraschall Med 2016; 37: 27-45

[3] Dietrich CF, Mueller G, Beyer-Enke S. Cysts in the cyst pattern. Z Gastroenterol. 2009; 47: 1203-1207

[4] Rhomberg F. [Therapy of filariasis]. Dtsch Med Wochenschr 1969; 94 : 1457

[5] Brunetti E, Tamarozzi F, Macpherson C, Filice C, Piontek MS, Kabaalioglu A, Dong Y et al. Ultrasound and cystic echinococcosis. Ultrasound Int Open 2018; 4: E70-E78

[6] Richter J, Azoulay D, Dong Y, Holtfreter MC, Akpata R, Calderaro J, El-Scheich T et al. Ultrasonography of gallbladder abnormalities due to schistosomiasis. Parasitol Res 2016; 115: 2917-2924

[7] Richter J, Botelho MC, Holtfreter MC, Akpata R, El Scheich T, Neumayr A, Brunetti E et al. Ultrasound assessment of schistosomiasis. Z Gastroenterol 2016; 54: 653-660

[8] Dietrich CF, Kabaalioglu A, Brunetti E, Richter J. Fasciolosis. Z Gastroenterol 2015; 53: 285-290

[9] Dietrich CF, Sharma M, Chaubal N, Dong Y, Cui XW, Schindler-Piontek M, Richter J et al. Ascariasis imaging: Pictorial essay. Z Gastroenterol 2017; 55: 479-489

[10] Christmann M, Henrich R, Mayer G, Ell C. [Infection with fasciola hepatica causing elevated liver-enzyme results and eosinophilia - serologic and endoscopic diagnosis and therapy]. Z Gastroenterol 2002; 40: 801-806

[11] Dietrich CF, Lembcke B, Jenssen C, Hocke M, Ignee A, Hollerweger A. Intestinal ultrasound in rare gastrointestinal diseases, update, part 1. Ultraschall Med 2014; 35: 400-421

[12] Dietrich CF, Lembcke B, Jenssen C, Hocke M, Ignee A, Hollerweger A. Intestinal ultrasound in rare gastrointestinal diseases, Update, Part 2. Ultraschall Med 2015; 36: 428-456

[13] Ramaiah KD, Ottesen EA. Progress and impact of 13 years of the global programme to eliminate lymphatic filariasis on reducing the burden of filarial disease. PLoS Negl Trop Dis 2014; 8: e3319

[14] Witt C, Ottesen EA. Lymphatic filariasis: An infection of childhood. Trop Med Int Health 2001; 6: 582-606

[15] Malhotra I, Mungai PL, Wamachi AN, Tisch D, Kioko JM, Ouma JH, Muchiri E et al. Prenatal T cell immunity to Wuchereria bancrofti and its effect on filarial immunity and infection susceptibility during childhood. J Infect Dis 2006; 193: 1005-1013

[16] Ottesen EA. The Wellcome Trust Lecture. Infection and disease in lymphatic filariasis: An immunological perspective. Parasitology 1992; 104: Suppl S71-S79

[17] Bennuru S, Nutman TB. Lymphatics in human lymphatic filariasis: In vitro models of parasite-induced lymphatic remodeling. Lymphat Res Biol 2009; 7: 215-219

[18] Grobusch MP, Kombila M, Autenrieth I, Mehlhorn H, Kremsner PG. No evidence of Wolbachia endosymbiosis with Loa loa and Mansonella perstans. Parasitol Res 2003; 90: 405-408 
[19] Taylor M], Hoerauf A. Wolbachia bacteria of filarial nematodes. Parasitol Today 1999; 15: 437-442

[20] Punkosdy GA, Addiss DG, Lammie PJ. Characterization of antibody responses to Wolbachia surface protein in humans with lymphatic filariasis. Infect Immun 2003; 71: 5104-5114

[21] Taylor M]. Wolbachia in the inflammatory pathogenesis of human filariasis. Ann NY Acad Sci 2003; 990: 444-449

[22] Taylor M], Cross HF, Ford L, Makunde WH, Prasad GB, Bilo K. Wolbachia bacteria in filarial immunity and disease. Parasite Immunol 2001; 23: 401-409

[23] Taylor M]. A new insight into the pathogenesis of filarial disease. Curr Mol Med 2002; 2: 299-302

[24] Lammie PJ, Cuenco KT, Punkosdy GA. The pathogenesis of filarial lymphedema: Is it the worm or is it the host? Ann NY Acad Sci 2002; 979: 131-142. discussion 188-196

[25] Nutman TB, Kazura J. Lymphatic Filariasis. In Guerrant R, Walker DH, Weller PF. (eds). Tropical Infectious Diseases: Principles, Pathogens and Practice. 3rd ed. Philadelphia: Saunders Elsevier; 2011

[26] Ottesen EA, Weller PF. Eosinophilia following treatment of patients with schistosomiasis mansoni and Bancroft's filariasis. J Infect Dis 1979; 139: 343-347

[27] Pani SP, Srividya A. Clinical manifestations of bancroftian filariasis with special reference to lymphoedema grading. Indian J Med Res 1995; 102: 114-118

[28] Pani SP, Yuvaraj J, Vanamail P, Dhanda V, Michael E, Grenfell BT, Bundy DA. Episodic adenolymphangitis and lymphoedema in patients with bancroftian filariasis. Trans R Soc Trop Med Hyg 1995; 89: $72-74$

[29] Dreyer G, Medeiros Z, Netto M], Leal NC, de Castro LG, Piessens WF. Acute attacks in the extremities of persons living in an area endemic for bancroftian filariasis: Differentiation of two syndromes. Trans $\mathrm{R}$ Soc Trop Med Hyg 1999; 93: 413-417

[30] McPherson T, Persaud S, Singh S, Fay MP, Addiss D, Nutman TB, Hay R. Interdigital lesions and frequency of acute dermatolymphangioadenitis in lymphoedema in a filariasis-endemic area. Br J Dermatol 2006; 154: 933-941

[31] Mand S, Debrah AY, Klarmann U, Batsa L, Marfo-Debrekyei Y, Kwarteng A, Specht $S$ et al. Doxycycline improves filarial lymphedema independent of active filarial infection: A randomized controlled trial. Clin Infect Dis 2012; 55: 621-630

[32] Supali T, Wibowo H, Ruckert P, Fischer K, Ismid IS, Purnomo Djuardi Y et al. High prevalence of Brugia timori infection in the highland of Alor Island, Indonesia. Am J Trop Med Hyg 2002; 66: 560-565

[33] Freedman DO, de Almeida Filho PJ, Besh S, Maia e Silva MC, Braga C, Maciel A. Lymphoscintigraphic analysis of lymphatic abnormalities in symptomatic and asymptomatic human filariasis. J Infect Dis 1994; 170: 927-933

[34] Dreyer G, Ottesen EA, Galdino E, Andrade L, Rocha A, Medeiros Z, Moura I et al. Renal abnormalities in microfilaremic patients with Bancroftian filariasis. Am J Trop Med Hyg 1992; 46: 745-751

[35] Franco-Paredes C, Hidron A, Steinberg J. A woman from British Guyana with recurrent back pain and fever. Chyluria associated with infection due to Wuchereria bancrofti. Clin Infect Dis 2006; 42: 1340-1291

[36] Sethi S, Misra K, Singh UR, Kumar D. Lymphatic filariasis of the ovary and mesosalpinx. J Obstet Gynaecol Res 2001; 27: 285-292

[37] Chandrasena TG, Premaratna R, Abeyewickrema W, de Silva NR. Evaluation of the ICT whole-blood antigen card test to detect infection due to Wuchereria bancrofti in Sri Lanka. Trans R Soc Trop Med Hyg 2002; 96: 60-63
[38] Chanteau S, Moulia-Pelat JP, Glaziou P, Nguyen NL, Luquiaud P, Plichart C, Martin PM et al. Og4C3 circulating antigen: A marker of infection and adult worm burden in Wuchereria bancrofti filariasis. J Infect Dis 1994; 170: 247-250

[39] Chesnais CB, Missamou F, Pion SD, Bopda J, Louya F, Majewski AC, Weil $G$ ] et al. Semi-quantitative scoring of an immunochromatographic test for circulating filarial antigen. Am J Trop Med Hyg 2013; 89: 916-918

[40] Rocha A, Addiss D, Ribeiro ME, Noroes J, Baliza M, Medeiros Z, Dreyer G. Evaluation of the Og4C3 ELISA in Wuchereria bancrofti infection: Infected persons with undetectable or ultra-low microfilarial densities. Trop Med Int Health 1996; 1: 859-864

[41] Turner P, Copeman B, Gerisi D, Speare R. A comparison of the Og4C3 antigen capture ELISA, the Knott test, an IgG4 assay and clinical signs, in the diagnosis of Bancroftian filariasis. Trop Med Parasitol 1993; 44: 45-48

[42] Weil G], Curtis KC, Fakoli L, Fischer K, Gankpala L, Lammie PJ, Majewski AC et al. Laboratory and field evaluation of a new rapid test for detecting Wuchereria bancrofti antigen in human blood. Am J Trop Med Hyg 2013; 89: 11-15

[43] Weil G], Ramzy RM. Diagnostic tools for filariasis elimination programs. Trends Parasitol 2007; 23: 78-82

[44] Kumar B, Karki S, Yadava SK. Role of fine needle aspiration cytology in diagnosis of filarial infestation. Diagn Cytopathol 2011; 39: 8-12

[45] Weil G], Jain DC, Santhanam S, Malhotra A, Kumar H, Sethumadhavan $\mathrm{KV}$, Liftis $\mathrm{F}$ et al. A monoclonal antibody-based enzyme immunoassay for detecting parasite antigenemia in bancroftian filariasis. J Infect Dis 1987; 156: 350-355

[46] Nicolas L, Plichart C, Nguyen LN, Moulia-Pelat JP. Reduction of Wuchereria bancrofti adult worm circulating antigen after annual treatments of diethylcarbamazine combined with ivermectin in French Polynesia. J Infect Dis 1997; 175: 489-492

[47] Bakajika DK, Nigo MM, Lotsima JP, Masikini GA, Fischer K, Lloyd MM, Weil G] et al. Filarial antigenemia and Loa loa night blood microfilaremia in an area without bancroftian filariasis in the Democratic Republic of Congo. Am J Trop Med Hyg 2014; 91: 1142-1148

[48] Pion SD, Montavon C, Chesnais CB, Kamgno J, Wanji S, Klion AD, Nutman TB et al. Positivity of antigen tests used for diagnosis of lymphatic filariasis in individuals without wuchereria bancrofti infection but with high loa loa microfilaremia. Am J Trop Med Hyg 2016; 95: 1417-1423

[49] McCarthy JS, Guinea A, Weil G], Ottesen EA. Clearance of circulating filarial antigen as a measure of the macrofilaricidal activity of diethylcarbamazine in Wuchereria bancrofti infection. J Infect Dis 1995; 172: 521-526

[50] Weil G], Lammie PJ, Richards FO Jr., Eberhard ML. Changes in circulating parasite antigen levels after treatment of bancroftian filariasis with diethylcarbamazine and ivermectin. J Infect Dis 1991; 164: 814-816

[51] Steel C, Golden A, Kubofcik ], LaRue N, de Los Santos T, Domingo G], Nutman TB. Rapid Wuchereria bancrofti-specific antigen Wb123based IgG4 immunoassays as tools for surveillance following mass drug administration programs on lymphatic filariasis. Clin Vaccine Immunol 2013; 20: 1155-1161

[52] Lammie PJ, Weil G, Noordin R, Kaliraj P, Steel C, Goodman D, Lakshmikanthan VB et al. Recombinant antigen-based antibody assays for the diagnosis and surveillance of lymphatic filariasis - A multicenter trial. Filaria J 2004; 3: 9

[53] Kubofcik J, Fink DL, Nutman TB. Identification of Wb123 as an early and specific marker of Wuchereria bancrofti infection. PLoS Negl Trop Dis 2012; 6: e1930

[54] Lucena WA, Dhalia R, Abath FG, Nicolas L, Regis LN, Furtado AF. Diagnosis of Wuchereria bancrofti infection by the polymerase chain reaction using urine and day blood samples from amicrofilaraemic patients. Trans R Soc Trop Med Hyg 1998; 92: 290-293 
[55] Ramzy RM, Farid HA, Kamal IH, Ibrahim GH, Morsy ZS, Faris R, Weil G] et al. A polymerase chain reaction-based assay for detection of Wuchereria bancrofti in human blood and Culex pipiens. Trans R Soc Trop Med Hyg 1997; 91: 156-160

[56] Dissanayake S, Rocha A, Noroes J, Medeiros Z, Dreyer G, Piessens WF. Evaluation of PCR-based methods for the diagnosis of infection in bancroftian filariasis. Trans R Soc Trop Med Hyg 2000; 94: 526-530

[57] Weller PF, Ottesen EA, Heck L, Tere T, Neva FA. Endemic filariasis on a Pacific island. I. Clinical, epidemiologic, and parasitologic aspects. Am J Trop Med Hyg 1982; 31: 942-952

[58] Mak JW, Cheong WH, Yen PK, Lim PK, Chan WC. Studies on the epidemiology of subperiodic Brugia malayi in Malaysia: Problems in its control. Acta Trop 1982; 39: 237-245

[59] Dreyer G, Figueredo-Silva J, Carvalho K, Amaral F, Ottesen EA. Lymphatic filariasis in children: Adenopathy and its evolution in two young girls. Am J Trop Med Hyg 2001; 65: 204-207

[60] Estran C, Marty P, Blanc V, Faure O, Leccia MT, Pelloux H, Diebolt E et al. [Human dirofilariasis: 3 cases in the south of France]. Presse Med 2007; 36: 799-803

[61] Aguiar-Santos AM, Leal-Cruz M, Netto M], Carrera A, Lima G, Rocha A. Lymph scrotum: An unusual urological presentation of lymphatic filariasis. A case series study. Rev Inst Med Trop Sao Paulo 2009; 51: 179-183

[62] Rocha A, Braga C, Belem M, Carrera A, Aguiar-Santos A, Oliveira P, Texeira M] et al. Comparison of tests for the detection of circulating filarial antigen (Og4C3-ELISA and AD12-ICT) and ultrasound in diagnosis of lymphatic filariasis in individuals with microfilariae. Mem Inst Oswaldo Cruz 2009; 104: 621-625

[63] Ilyasov B, Kartashev V, Bastrikov N, Madjugina L, Gonzalez-Miguel ], Morchon R, Simon F. Thirty cases of human subcutaneous dirofilariasis reported in Rostov-on-Don (Southwestern Russian Federation). Enferm Infecc Microbiol Clin 2015; 33: 233-237

[64] Cohen LB, Nelson G, Wood AM, Manson-Bahr PE, Bowen R. Lymphangiography in filarial lymphoedema and elephantiasis. Am J Trop Med Hyg 1961; 10: 843-848

[65] Gandhi GM. Role of lymphography in management of filarial chyluria. Lymphology 1976; 9: 11-18

[66] Dustmann HO. [Diagnosis, differential diagnosis and therapy of lymphedema]. Z Orthop Ihre Grenzgeb 1982; 120: 76-82

[67] Lymphatic filariasis: Siagnosis and pathogenesis. WHO expert committee on filariasis. Bull World Health Organ 1993; 71: 135-141

[68] Shelley S, Manokaran G, Indirani M, Gokhale S, Anirudhan N. Lymphoscintigraphy as a diagnostic tool in patients with lymphedema of filarial origin-an Indian study. Lymphology 2006; 39: 69-75

[69] Amaral F, Dreyer G, Figueredo-Silva J, Noroes J, Cavalcanti A, Samico SC, Santos A et al. Live adult worms detected by ultrasonography in human Bancroftian filariasis. Am J Trop Med Hyg 1994; 50: 753-757

[70] Noroes J, Addiss D, Amaral F, Coutinho A, Medeiros Z, Dreyer G. Occurrence of living adult Wuchereria bancrofti in the scrotal area of men with microfilaraemia. Trans R Soc Trop Med Hyg 1996; 90: $55-56$

[71] Dreyer G, Noroes J, Addiss D, Santos A, Medeiros Z, Figueredo-Silva J. Bancroftian filariasis in a paediatric population: An ultrasonographic study. Trans R Soc Trop Med Hyg 1999; 93: 633-636

[72] Simonsen PE, Bernhard P, Jaoko WG, Meyrowitsch DW, Malecela-Lazaro MN, Magnussen P, Michael E. Filaria dance sign and subclinical hydrocoele in two east African communities with bancroftian filariasis. Trans R Soc Trop Med Hyg 2002; 96: 649-653

[73] Chaubal NG, Pradhan GM, Chaubal JN, Ramani SK. Dance of live adult filarial worms is a reliable sign of scrotal filarial infection. J Ultrasound Med 2003; 22: 765-769. quiz 770-762

[74] Shetty GS, Solanki RS, Prabhu SM, Jawa A. Filarial dance-sonographic sign of filarial infection. Pediatr Radiol 2012; 42: 486-487
[75] Bayramoglu Z, Yilmaz R, Gocmez A, Salmaslioglu A, Acunas G. Filarial dance in the axillary lymph node. Breast J 2017; 23: 474-475

[76] Dreyer G, Noroes J, Amaral F, Nen A, Medeiros Z, Coutinho A, Addiss D. Direct assessment of the adulticidal efficacy of a single dose of ivermectin in bancroftian filariasis. Trans R Soc Trop Med Hyg 1995; 89: $441-443$

[77] Noroes J, Dreyer G, Santos A, Mendes VG, Medeiros Z, Addiss D. Assessment of the efficacy of diethylcarbamazine on adult Wuchereria bancrofti in vivo. Trans R Soc Trop Med Hyg 1997; 91: 78-81

[78] Mand S, Debrah A, Batsa L, Adjei O, Hoerauf A. Reliable and frequent detection of adult Wuchereria bancrofti in Ghanaian women by ultrasonography. Trop Med Int Health 2004; 9: 1111-1114

[79] Shenoy RK, Suma TK, Kumaraswami V, Padma S, Rahmah N, Abhilash G, Ramesh C. Doppler ultrasonography reveals adult-worm nests in the lymph vessels of children with brugian filariasis. Ann Trop Med Parasitol 2007; 101: 173-180

[80] Shenoy RK, Suma TK, Kumaraswami V, Rahmah N, Dhananjayan G Padma S, Abhilash $G$ et al. Preliminary findings from a cross-sectional study on lymphatic filariasis in children, in an area of India endemic for Brugia malayi infection. Ann Trop Med Parasitol 2007; 101: 205-213

[81] Mand S, Marfo-Debrekyei Y, Dittrich M, Fischer K, Adjei O, Hoerauf A. Animated documentation of the filaria dance sign (FDS) in bancroftian filariasis. Filaria J 2003; 2: 3

[82] Shenoy RK, John A, Hameed S, Suma TK, Kumaraswami V. Apparent failure of ultrasonography to detect adult worms of Brugia malayi. Ann Trop Med Parasitol 2000; 94: 77-82

[83] Reddy GS, Das LK, Pani SP. The preferential site of adult Wuchereria bancrofti: An ultrasound study of male asymptomatic microfilaria carriers in Pondicherry, India. Natl Med J India 2004; 17: 195-196

[84] Mand S, Debrah AY, Klarmann U, Mante S, Kwarteng A, Batsa L, Marfo-Debrekyei $Y$ et al. The role of ultrasonography in the differentiation of the various types of filaricele due to bancroftian filariasis. Acta Trop 2011; 120: Suppl 1 S23-S32

[85] Dreyer G, Brandao AC, Amaral F, Medeiros Z, Addiss D. Detection by ultrasound of living adult Wuchereria bancrofti in the female breast. Mem Inst Oswaldo Cruz 1996; 91: 95-96

[86] Patil JA, Patil AD, Ramani SK. Filarial “dance” in breast mass. AJR Am J Roentgenol 2003; 181: 1157-1158

[87] Hocke M, Ignee A, Dietrich C. Role of contrast-enhanced endoscopic ultrasound in lymph nodes. Endosc Ultrasound 2017; 6: 4-11

[88] Chiorean L, Cui XW, Klein SA, Budjan J, Sparchez Z, Radzina M, Jenssen $C$ et al. Clinical value of imaging for lymph nodes evaluation with particular emphasis on ultrasonography. Z Gastroenterol 2016; 54: 774-790

[89] Dietrich CF. Contrast-enhanced endobronchial ultrasound: Potential value of a new method. Endosc Ultrasound 2017; 6: 43-48

[90] Ignee A, Atkinson NS, Schuessler G, Dietrich CF. Ultrasound contrast agents. Endosc Ultrasound 2016; 5: 355-362

[91] Jenssen C, Annema JT, Clementsen P. Ultrasound techniques in the evaluation of the mediastinum, part 2: Mediastinal lymph node anatomy and diagnostic reach of ultrasound techniques, clinical work up of neoplastic and inflammatory mediastinal lymphadenopathy using ultrasound techniques and how to learn mediastinal endosonography. J Thorac Dis 2016; 7: E439

[92] Dietrich CF, Jenssen C, Herth F]. Endobronchial ultrasound elastography. Endosc Ultrasound 2016; 5: 233-238

[93] Dietrich CF, Annema JT, Clementsen P, Cui XW, Borst MM, Jenssen C. Ultrasound techniques in the evaluation of the mediastinum, part I: Endoscopic ultrasound (EUS), endobronchial ultrasound (EBUS) and transcutaneous mediastinal ultrasound (TMUS), introduction into ultrasound techniques. J Thorac Dis 2015; 7: E311-E325 
[94] Schreiber-Dietrich D, Pohl M, Cui XW, Braden B, Dietrich CF, Chiorean L. Perihepatic lymphadenopathy in children with chronic viral hepatitis. J Ultrason 2015; 15: 137-150

[95] Cui XW, Hocke M, Jenssen C, Ignee A, Klein S, Schreiber-Dietrich D, Dietrich CF. Conventional ultrasound for lymph node evaluation, update 2013. Z Gastroenterol 2014; 52: 212-221

[96] Dietrich CF, Averkiou M, Nielsen MB, Barr RG, Burns PN, Calliada F, Cantisani $V$ et al. How to perform Contrast-Enhanced Ultrasound (CEUS). Ultrasound Int Open 2018; 4: E2-E15

[97] Sidhu PS, Cantisani V, Deganello A, Dietrich CF, Duran C, Franke D, Harkanyi $Z$ et al. Role of Contrast-Enhanced Ultrasound (CEUS) in Paediatric Practice: An EFSUMB Position Statement. Ultraschall Med 2017; 38: 33-43

[98] Trimboli P, Dietrich CF, David E, Mastroeni G, Ventura Spagnolo O, Sidhu PS, Letizia $C$ et al. Ultrasound and ultrasound-related techniques in endocrine diseases. Minerva Endocrinol 2018; 43: 333-340

[99] Dietrich CF, Rudd L, Saftiou A, Gilja OH. The EFSUMB website, a great source for ultrasound information and education. Med Ultrason 2017; 19: 102-110

[100] Dong Y, D'Onofrio M, Hocke M, Jenssen C, Potthoff A, Atkinson N, Ignee $A$ et al. Autoimmune pancreatitis: Imaging features. Endosc Ultrasound 2018; 7: 196-203

[101] Dong Y, Jurgensen C, Puri R, D’Onofrio M, Hocke M, Wang WP, Atkinson $\mathrm{N}$ et al. Ultrasound imaging features of isolated pancreatic tuberculosis. Endosc Ultrasound 2017; 7: 119-127

[102] Dietrich CF, Greis C. [How to perform contrast enhanced ultrasound]. Dtsch Med Wochenschr 2016; 141: 1019-1024

[103] Barr RG, Cosgrove D, Brock M, Cantisani V, Correas JM, Postema AW, Salomon G et al. WFUMB guidelines and recommendations on the clinical use of ultrasound elastography: Part 5. Prostate. Ultrasound Med Biol 2017; 43: 27-48

[104] Cosgrove D, Barr R, Bojunga J, Cantisani V, Chammas MC, Dighe M, Vinayak $S$ et al. WFUMB guidelines and recommendations on the clinical use of ultrasound elastography: Part 4. Thyroid. Ultrasound Med Biol 2017; 43: 4-26

[105] Hocke M, Braden B, Jenssen C, Dietrich CF. Present status and perspectives of endosonography 2017 in gastroenterology. Korean J Intern Med 2018; 33: 36-63

[106] Berzigotti A, Ferraioli G, Bota S, Gilja OH, Dietrich CF. Novel ultrasound-based methods to assess liver disease: The game has just begun. Dig Liver Dis 2018; 50: 107-112

[107] Dietrich CF, Ponnudurai R, Bachmann Nielsen M. [Is there a need for new imaging methods for lymph node evaluation?]. Ultraschall Med 2012; 33: 411-414

[108] Cui XW, Ignee A, Bachmann Nielsen M, Schreiber-Dietrich D, Demolo C, Pirri C, Jedrejczyk $M$ et al. Contrast enhanced ultrasound of sentinel lymph nodes. Journal of Ultrasonography 2013; 13: 73-81

[109] Jung J, Chang J, Oh S, Yoon J, Choi M. Computed tomography angiography for evaluation of pulmonary embolism in an experimental model and heartworm infested dogs. Vet Radiol Ultrasound 2010; 51: 288-293

[110] Takahashi A, Yamada K, Kishimoto M, Shimizu J, Maeda R. Computed tomography (CT) observation of pulmonary emboli caused by long-term administration of ivermectin in dogs experimentally infected with heartworms. Vet Parasitol 2008; 155: 242-248

[111] Oshiro Y, Murayama S, Sunagawa U, Nakamoto A, Owan I, Kuba M, Uehara T et al. Pulmonary dirofilariasis: Computed tomography findings and correlation with pathologic features. J Comput Assist Tomogr 2004; 28: 796-800
[112] Martin TN, Weir RA, Dargie HJ. Contrast-enhanced magnetic resonance imaging of endomyocardial fibrosis secondary to Bancroftian filariasis. Heart 2008; 94: 1116

[113] Shukla-Dave A, Degaonkar M, Roy R, Murthy PK, Murthy PS, Raghunathan P, Chatterjee RK. Metabolite mapping of human filarial parasite, Brugia malayi with nuclear magnetic resonance. Magn Reson Imaging 1999; 17: 1503-1509

[114] Blacksin MF, Lin SS, Trofa AF. Filariasis of the ankle: Magnetic resonance imaging. Foot Ankle Int 1999; 20: 738-740

[115] Shukla-Dave A, Fatma N, Roy R, Srivastava S, Chatterjee RK, Govindaraju V, Viswanathan AK et al. $1 \mathrm{H}$ magnetic resonance imaging and 31P magnetic resonance spectroscopy in experimental filariasis. Magn Reson Imaging 1997; 15: 1193-1198

[116] Tekola Ayele F, Adeyemo A, Finan C, Hailu E, Sinnott P, Burlinson ND, Aseffa A et al. HLA class II locus and susceptibility to podoconiosis. N Engl J Med 2012; 366: 1200-1208

[117] Wanji S, Amvongo-Adjia N, Koudou B, Njouendou AJ, Chounna Ndongmo PW, Kengne-Ouafo JA, Datchoua-Poutcheu FR et al. Cross-reactivity of filariais ICT Cards in areas of contrasting endemicity of loa loa and mansonella perstans in cameroon: Implications for Shrinking of the lymphatic filariasis map in the central african region. PLoS Negl Trop Dis 2015; 9: e0004184

[118] Wanji S, Amvongo-Adjia N, Njouendou AJ, Kengne-Ouafo JA, Ndongmo WP, Fombad FF, Koudou B et al. Further evidence of the cross-reactivity of the Binax NOW(R) Filariasis ICT cards to non-Wuchereria bancrofti filariae: Experimental studies with Loa loa and Onchocerca ochengi. Parasit Vectors 2016; 9: 267

[119] Hoerauf A. Filariasis: New drugs and new opportunities for lymphatic filariasis and onchocerciasis. Curr Opin Infect Dis 2008; 21: 673-681

[120] Moore TA, Reynolds JC, Kenney RT, Johnston W, Nutman TB. Diethylcarbamazine-induced reversal of early lymphatic dysfunction in a patient with bancroftian filariasis: Assessment with use of lymphoscintigraphy. Clin Infect Dis 1996; 23: 1007-1011

[121] Tisch DJ, Michael E, Kazura JW. Mass chemotherapy options to contro lymphatic filariasis: A systematic review. Lancet Infect Dis 2005; 5: 514-523

[122] Frayha GJ, Smyth JD, Gobert JG, Savel J. The mechanisms of action of antiprotozoal and anthelmintic drugs in man. Gen Pharmacol 1997; 28: 273-299

[123] Maizels RM, Bundy DA, Selkirk ME, Smith DF, Anderson RM. Immunological modulation and evasion by helminth parasites in human populations. Nature 1993; 365: 797-805

[124] Klion AD, Ottesen EA, Nutman TB. Effectiveness of diethylcarbamazine in treating loiasis acquired by expatriate visitors to endemic regions: Long-term follow-up. J Infect Dis 1994; 169: 604-610

[125] Addiss DG, Beach MJ, Streit TG, Lutwick S, LeConte FH, Lafontant JG, Hightower AW et al. Randomised placebo-controlled comparison of ivermectin and albendazole alone and in combination for Wuchereria bancrofti microfilaraemia in Haitian children. Lancet 1997; 350: 480-484

[126] Cao WC, Van der Ploeg CP, Plaisier AP, van der Sluijs IJ, Habbema JD. Ivermectin for the chemotherapy of bancroftian filariasis: A meta-analysis of the effect of single treatment. Trop Med Int Health 1997; 2: 393-403

[127] Chodakewitz ]. Ivermectin and Lymphatic Filariasis: A clinical update. Parasitol Today 1995; 11: 233

[128] Gardon J, Gardon-Wendel N, Demanga N, Kamgno J, Chippaux JP, Boussinesq M. Serious reactions after mass treatment of onchocerciasis with ivermectin in an area endemic for Loa loa infection. Lancet 1997; 350: 18-22

[129] Ottesen EA, Vijayasekaran V, Kumaraswami V, Perumal Pillai SV, Sadanandam A, Frederick S, Prabhakar R et al. A controlled trial of ivermectin and diethylcarbamazine in lymphatic filariasis. $N$ Engl ] Med 1990; 322: 1113-1117 
[130] Greene BM, Taylor HR, Cupp EW, Murphy RP, White AT, Aziz MA, Schulz-Key $\mathrm{H}$ et al. Comparison of ivermectin and diethylcarbamazine in the treatment of onchocerciasis. N Engl J Med 1985; 313: 133-138

[131] Lariviere M, Vingtain P, Aziz M, Beauvais B, Weimann D, Derouin F, Ginoux J et al. Double-blind study of ivermectin and diethylcarbamazine in African onchocerciasis patients with ocular involvement. Lancet 1985; 2: 174-177

[132] Taylor M], Hoerauf A, Bockarie M. Lymphatic filariasis and onchocerciasis. Lancet 2010; 376: 1175-1185

[133] Dreyer G, Addiss D, Williamson J, Noroes J. Efficacy of co-administered diethylcarbamazine and albendazole against adult Wuchereria bancrofti. Trans R Soc Trop Med Hyg 2006; 100: 1118-1125

[134] Gayen P, Nayak A, Saini P, Mukherjee N, Maitra S, Sarkar P, Sinha Babu SP. A double-blind controlled field trial of doxycycline and albendazole in combination for the treatment of bancroftian filariasis in India. Acta Trop 2013; 125: 150-156

[135] Hopkins DR. Disease eradication. N Engl J Med 2013; 368: 54-63
[136] Kroidl I, Saathof E, Maganga L, Clowes P, Maboko L, Hoerauf A, Makunde WH et al. Prevalence of Lymphatic filariasis and treatment effectiveness of albendazole/ivermectin in individuals with HIV co-infection in Southwest-Tanzania. PLoS Negl Trop Dis 2016; 10: e0004618

[137] Ottesen EA. Major progress toward eliminating lymphatic filariasis. N Engl J Med 2002; 347: 1885-1886

[138] Thomas G, Richards FO Jr., Eigege A, Dakum NK, Azzuwut MP, Sarki ], Gontor I et al. A pilot program of mass surgery weeks for treatment of hydrocele due to lymphatic filariasis in central Nigeria. Am J Trop Med Hyg 2009; 80: 447-451

[139] 489 Global programme to eliminate lymphatic filariasis: Progress report. 2014. Wkly Epidemiol Rec. 2015; 90: 489-504

[140] Thomsen EK, Sanuku N, Baea M, Satofan S, Maki E, Lombore B, Schmidt MS et al. Efficacy, Safety, and pharmacokinetics of coadministered diethylcarbamazine, albendazole, and ivermectin for treatment of bancroftian filariasis. Clin Infect Dis 2016; 62: 334-341 